\title{
EUNIS 2013: BENCHEIT - Benchmarking Higher Education IT
}

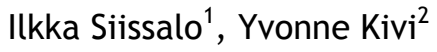 \\ ${ }^{1} \mathrm{ClO}$, University of Helsinki, P.O. Box 28 (Koetilantie 3), 00014 University of Helsinki, \\ ilkka.siissalo@helsinki.fi \\ ${ }^{2}$ Project manager, P.O. Box 28 (Koetilantie 3), 00014 University of Helsinki, yvonne.kivi@helsinki.fi
}

Keywords

Bencheit, IT benchmarking, survey, IT volumes, IT costs.

\section{BENCHEIT}

The BENCHEIT group is one of the official task forces of EUNIS. BENCHEIT is a project group running an annual survey of IT volumes and costs throughout European higher education institutes. BENCHEIT is the first serious European level effort to compare IT costs and volumes throughout European higher education institutes. Our principles are: Low (or no) cost, voluntary work, total openness with the data for all participants, total cooperation across institutes. Universities often compete against each other - but we do not compete in IT. This is the area to help each other!

\section{KNOW YOUR NUMBERS}

Every serious IT manager or IT director should of course always be interested in knowing whether the amount of effort and money his or her institution is spending on IT is "right". But what is "right" for a certain size and type of institution? You only know if you compare. Previously only US based surveys or commercial, extremely expensive surveys have been available. However, personnel costs in USA differ really a lot from European higher education organisations' costs, so direct comparisons may be irrelevant. On the other hand, commercial surveys most often only measure us against commercial companies, disregarding academic pricing models, so again we may end up comparing our efforts with something totally different.

\section{COMPARE WITH PEERS}

Benchmarking is a tool for following the costs of operations and comparing it to peer institutions. There are a lot of benefits, but maybe the most important thing is that you learn about your own (in this case IT) environment, and understand your position amongst the competition. The knowledge of how others are doing things can also help you see how you actually follow through your own strategy, direct resources to the right things and improve your performance. This year almost every Finnish $\mathrm{HEl}$ is participating, and we also have 13 registered European HEls.

\section{OPEN FOR EVERYONE}

In Finland two pilot rounds have been done, the first in 2011 and a second in 2012. A lot of work has been done to make the survey form easier to use and the questions easier to understand. The survey was translated into English, because the aim from the beginning has been to open the survey to every European HEl interested. The Bencheit project group arrange workshops, and also runs as a helpdesk for the participants, to ensure that as many universities as possible will actually complete the survey.

The survey is measuring costs of IT, the degree of centralisation of IT and the volumes (numbers of workstations, servers etc). It is a valuable tool for any higher education institute $\mathrm{ClO}$ for positioning and comparing one's own organisation with peers within Europe. This round concentrates especially on helping the institutions find peer institutions that are the most interesting to compare themselves to.

For more information please see www. bencheit.info 


\section{ABOUT THE AUTHORS}

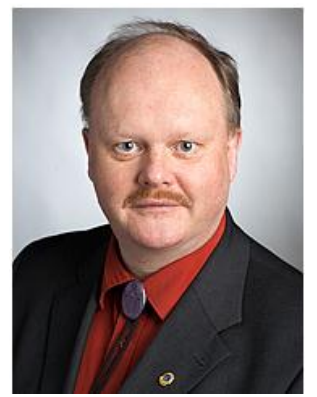

Ilkka Siisalo is $\mathrm{ClO}$ at the University of Helsinki since 2005. Prior to that, he has worked in the pharmaceutical industry, with research and later IT. He is Head of the Center for Information Technology, serving both the University of Helsinki and other smaller universities in Finland. The IT department has around 220 employees.

In addition to strategic planning, information security and supervision, which are the key responsibilities for IT management, Ilkka also handles both national and international partners in cooperation. He is also a member of the EUNIS board.

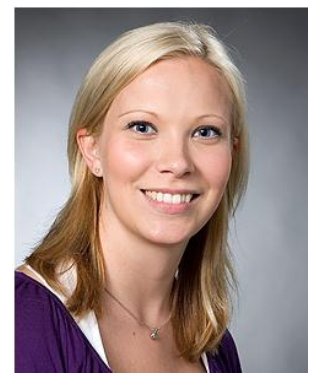

Yvonne Kivi works at the IT Management at the University of Helsinki. She is a project manager for the Bencheit project since the end of 2011. The practical work in the project is done by the project group, which has members from all over Finland. The thought is to also have members from other European countries in the future.

She is responsible for the data gathering for the University of Helsinki part, and handles the international contacts in the project. 